\title{
Enhanced adsorptive removal of Indigo carmine dye performance by functionalized carbon nanotubes based adsorbents from aqueous solution: equilibrium, kinetic, and DFT study
}

\author{
Zeinab Hoseini Dastgerdi $^{1} \cdot$ Seyyed Salar Meshkat ${ }^{1}\left[\right.$ ? Mehdi D. Esrafili $^{2}$
}

Received: 31 August 2019 / Accepted: 9 November 2019 / Published online: 16 November 2019

(c) The Author(s) 2019

\begin{abstract}
The present work considers an adsorptive removal of Indigo carmine (IC) dye onto nanotube carbon (CNTs). The pure CNTs were prepared via chemical vapor deposition (CVD) method utilizing methane gas as a carbon source at $1000{ }^{\circ} \mathrm{C}$ in a quartz tube. The morphology and surface chemical structure of the adsorbents were characterized by scanning electron microscopy (SEM), X-ray diffraction (XRD), Fourier transform infrared spectroscopy (FTIR), nitrogen adsorption/desorption technique, and thermal gravity analysis (TGA). The parameters of the IC dye adsorption, such as initial concentration, contact time, $\mathrm{pH}$, and mass-loaded adsorbent, were evaluated. The kinetic study confirmed that a pseudo-second-order model was best fitted to the adsorption data. The removal efficiency of adsorption onto pure and COOH-functionalized CNTs was $84 \%$ and 98.7\% at $15 \mathrm{~min}$, respectively. The equilibrium results were fitted well to the Langmuir isotherm model. The adsorption capacity of the CNT and COOH-CNT was 88.5 and $136 \mathrm{mg} / \mathrm{g}$, respectively. The reusability of the adsorbents was studied, and after eight cycles, the efficiency decreased to $70 \%$. Moreover, the density functional theory calculations confirmed that the functionalization of CNTs with $\mathrm{COOH}$ groups improves the adsorption properties of IC due to the formation of hydrogen-bonding interactions.
\end{abstract}

Keywords Indigo carmine $\cdot$ Adsorption $\cdot$ Langmuir $\cdot$ Carbon nanotube $\cdot$ Regeneration

\section{Introduction}

Dye affects human health directly, so the water treatment process is expanded with a significantly increasing trend. The existence of a double bond in the structure of IC dye causes it to be a permanent dye that is being utilized in the industry for coloring. There are salts and organic materials in the wastewater of the textile dye in a high amount. However, this dye harms the lives of humans, as it is carcinogenic, and

Electronic supplementary material The online version of this article (https://doi.org/10.1007/s40097-019-00321-0) contains supplementary material, which is available to authorized users.

Seyyed Salar Meshkat

s.meshkat@che.uut.ac.ir

1 Faculty of Chemical Engineering, Urmia University of Technology, Urmia, Iran

2 Laboratory of Theoretical Chemistry, Department of Chemistry, University of Maragheh, P.O. Box: 5513864596, Maragheh, Iran leads to allergy [1-3]. Moreover, disturbances of IC on the environment are noticeable and hence pose many threats to the ecosystem. Various dye removal methods from wastewater are available. These include ultrafiltration [4], electrochemical [5], and adsorption [6] techniques. Unfortunately, the utilization of the above methods has some crucial such as low removal efficiency, expensive cost, and catalytic reduction [7-9]. Among these dye removal techniques, adsorption is highlighted as an advanced, efficient, and economical method in low temperature and pressure conditions with a low-cost adsorbent. The adsorption process is the most conventional method. In this regard, vast numbers of low-cost adsorbents have been studied to remove such pollutants [9]. Various materials have been concerned for adsorption of dyes for water treatment, such as biomass-derived adsorbents $[10,11]$. Studies focused that activated carbons are suitable and promising adsorbent for organic water pollutants. The wastewater treatment with activated carbon is an effective method. Activated carbon is being extensively employed to remove unpleasant compounds, including different dyes, pigments, and other pollutants [12]. Activated carbon is 


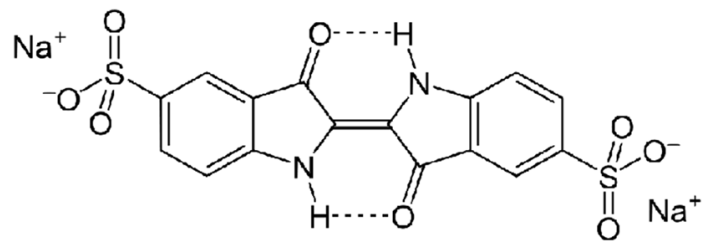

Fig. 1 Schematic of the Indigo carmine dye

one of the considerable potentials in treating wastewater, as it possesses high surface area, high efficiency in removing dyes, and high adsorption capacity. Most of the pollutants which are present in wastewater could be removed by active carbon synthesized from different sources [12, 13].

Because of the large surface area, low cost, facile synthesis, and $\pi$-electrons on the surface, easy availability, and various functional groups on the surface of the CNTs, these carbonous honey ball structures have found many potential applications in different research fields like of water purification $[14,15]$. One of the effective treatment methods of wastewaters is considered with carbon nanotubes for the removal of various dye from waste solution due to its large surface area, porous nature, high adsorption capacity, high purity, and easy availability [1, 14]. Lin and Xing [14] have evaluated the adsorption of aromatic compounds with the aid of carbon nanotubes. They confirmed that the adsorption of aromatic compounds by CNTs increases with increasing the number of aromatic rings and was greatly enhanced by $-\mathrm{OH}$ substitution. They also investigated the role of aromatic structure and $-\mathrm{OH}$ substitution in the polar aromatics-CNTs' structure.

Figure 1 shows the IC schematic, including four benzene rings with a double link inside them and two sulfonated negative-charged groups [16]. As the chemical structure of the IC dye is complicated, so the novel, economical, low-cost adsorbents should be introduced to the industry. Recently, researchers [17, 18] have attracted the vast usage of the nanomaterial because of the large specific area and high reactivity and simplicity in surface functionality.

This research focuses on dye removal through adsorption by utilization of an adsorbent, where the equilibrium content of the adsorbed IC dye, the amount of used adsorbent, temperature, duration of the adsorption process, and $\mathrm{pH}$ of the solution are studied. In the evaluation of the adsorption parameters, the optimum values of the parameters are calculated by changing one parameter and keeping the other one constant. By the combination of experimental results and density functional theory simulations, we study the adsorbent capacity of the pure and $\mathrm{COOH}$ functionalized carbon nanotubes (CNTs), and also compare the kinetics, isotherm, and adsorption capacity of the adsorbents to select the appropriate adsorbent for IC dye removal.

\section{Materials and methods}

\section{Adsorbents}

\section{Synthesis of CNTs}

The synthesis of CNTs as adsorbents was carried out by chemical vapor deposition (CVD) protocol [19]. The catalytic reaction was utilized by $\mathrm{Co}-\mathrm{Mo} / \mathrm{MgO}$ catalyst in a quartz tube furnace reactor at $1000{ }^{\circ} \mathrm{C}$ for $30 \mathrm{~min}$. The CVD reaction was performed using methane and hydrogen as a carbon source. The flow rate of the methane was $50 \mathrm{ml} / \mathrm{min}$, and hydrogen passes through the tubular reactor with a $250 \mathrm{ml} / \mathrm{min}$ flow rate as the carrier gas. The furnace temperature was decreased and cooled to room temperature under argon atmosphere. After completion of the reaction, the black material was synthesized. The black product is mixed with $\mathrm{HCl}$ solution for about $16 \mathrm{~h}$, due to refine the synthesized CNT and then wash with distillate water several times to maintain the $\mathrm{pH}$ in the neutral range.

\section{Synthesis of CNT-COOH}

To prepare the CNTs with carboxylic functionalized groups ( $\mathrm{COOH}-\mathrm{CNT})$, sulfuric acid, and nitric acid was stirred with a $3: 1$ volumetric ratio, and then, CNTs were dispersed into above solution and sonicated for 3 hours. After that, the CNTs were washed with deionized water until the neutral solution $\mathrm{pH}$, and then, the mixture was filtered and dried at $120{ }^{\circ} \mathrm{C}$. The recited procedure is designed to synthesize the functionalized carbon nanotubes with covalent carboxylic groups ( $\mathrm{COOH}-\mathrm{CNTs})$.

\section{Adsorption experiment}

The series of batch adsorption experiments were performed in a $250 \mathrm{ml}$ flask with the utilization of CNT and $\mathrm{CNT}-\mathrm{COOH}$ as adsorbents. According to the procedure [20], $1 \mathrm{~g}$ of adsorbent was added to a $100 \mathrm{ml}$ solution containing IC dye with various concentrations. The flasks were shaken by rotary shaker (ASRS-124 G25 model) with $200 \mathrm{rpm}$ at $25{ }^{\circ} \mathrm{C}$ for $30 \mathrm{~min}$. The effect of the adsorption process parameters such as temperature, time contact, mass loaded, and dye concentration was investigated, and the optimum values were achieved. UV-visible spectrophotometric detector (Shimadzu, Kyoto, Japan), which was set at $215 \mathrm{~nm}$, determined the equilibrium concentration of the solution after the adsorption process. Equations calculated the values of the adsorption capacity of both 
adsorbents (CNT and $\mathrm{COOH}-\mathrm{CNT})$ and the removal efficiency of the adsorbent. Eqs. 1 and 2, [21], respectively:

$q=\frac{\left(C_{0}-C_{e}\right)}{m} \times V$

$\operatorname{Removal}(\%)=\frac{C_{0}-C_{e}}{C_{0}} \times 100$,

where $q$ is the adsorbent capacity $(\mathrm{mg} / \mathrm{g}), C_{0}$, and $C_{\mathrm{e}}$ are the initial dye concentration and equilibrium adsorbate concentration $(\mathrm{mg} / \mathrm{l})$, respectively, $m$ is mass loaded of adsorbent $(\mathrm{g})$, and $V$ is the volume of the solution (ml).

\section{Kinetic modeling}

A kinetic study was introduced to determine the rate-controlling step and rate constant of the IC adsorption onto the prepared adsorbents. In this research, the kinetic modeling study was checked by pseudo-first-order, pseudo-secondorder, and intraparticle models. Equation 3 shows the linear form of the pseudo-first-order model [21]:

$\ln \left(q_{e}-q\right)=\ln \left(q_{e}\right)-k_{1} t$

where $q_{e}$ and $q$ are the IC-adsorbed amount in $\mathrm{mg} / \mathrm{g}$ at equilibrium time and contact time, and $k_{1}$ is the kinetic rate constant of pseudo-first-order model, which is accrued from the slope of the $\ln \left(q_{e}-q\right)$ vs. time linear regression.

Pseudo-second-order model constants [21] are calculated from Eq. 4:

$\frac{t}{q}=\frac{1}{k_{2} \times q_{e}^{2}}+\frac{t}{q_{e}}$,

where $q_{e}$ and $q$ are adsorbent capacities at equilibrium and respective time, and $k_{2}$ is the pseudo-second-order rate constant. $q_{e}$ and $k_{2}$ are calculated from the slope and intercept of the linear regression of the $t / q$ vs. time.

Weber and Morris have announced the intraparticle diffusion model to distinguish the mass transfer resistance of the adsorption process onto the adsorbent [21]. The model is given by Eq. 5 :

$q=k_{i} \times t^{1 / 2}+C$,

where $k_{i}$ is the intraparticle model constant which is calculated from the slope of Eq. 5. The parameter $C$, a constant related to the thickness of the boundary layer, was obtained from the intercept of Eq. 5 .

\section{Isotherm study}

Adsorbent capacity was evaluated from equilibrium data and adsorption isotherm studies. The isotherm equilibrium data were calculated from different concentration solutions of the dye adsorption. In this present work, two models were revealed and consist of Langmuir and Freundlich models. In Eq. 6, the linear form of the Langmuir model [1,22] is given, which in the Langmuir model, the adsorption process is assumed to do on a homogeneous surface by monolayer adsorption:

$\frac{C_{e}}{q_{e}}=\frac{1}{b \times Q_{0}}+\frac{C_{e}}{Q_{0}}$,

where the adsorbent equilibrium capacity is indicated by $q_{e}$ $(\mathrm{mg} / \mathrm{g}), C_{e}$ is the equilibrium concentration of the adsorbate $(\mathrm{mg} / \mathrm{L}), Q_{0}$ is the adsorption capacity of the monolayer $(\mathrm{mg} / \mathrm{g})$ and $b$ is the adsorption constant of the free energy.

As known, the Freundlich model $[1,22]$ assumes the multilayer with reversible adsorption on the non-uniform distribution of the active site. Equation 7 includes the linear form of the Freundlich model. $k_{F}$ and $n$ reflect the Freundlich parameter, which $n$ implies a scale of the heterogeneity of the adsorbent surface:

$\ln \left(q_{e}\right)=\ln \left(k_{f}\right)+\frac{1}{n} \ln \left(C_{e}\right)$,

where $q_{e}$ indicates the equilibrium adsorption capacity in $\mathrm{mg} / \mathrm{g}$, and $C_{e}$ is the IC dye concentration at equilibrium in $\mathrm{mg} / \mathrm{l}, k_{f}$, and $n$ are obtained from the slope and intercept of the linear equation of the $\ln \left(q_{e}\right)$ vs. $\ln \left(C_{e}\right)$.

In the Tempkin isotherm model, the heat of adsorption should decrease linearly with the surface coverage. The Tempkin isotherm constant, $A_{T}$ in $\mathrm{l} / \mathrm{g}$, and $B$ in $\mathrm{J} / \mathrm{mol}$ are related to the heat of adsorption. In Tempkin isotherm assumption, the interaction between the adsorbate and adsorbent is highlighted $[1,22]$ :

$q_{e}=B \operatorname{Ln}\left(A_{T}\right)+B \operatorname{Ln}\left(C_{e}\right)$.

In Dubinin-Radushkevich (D-R) isotherm model (Eq. 9), $q_{s}$ is the D-R constant, and $\varepsilon$ can be obtained from Eq. 10 . $R=8.314(\mathrm{~J} / \mathrm{mol} \mathrm{K})$ is the gas constant, and $T$ indicates the temperature in ${ }^{\circ} \mathrm{K}$. In Eq. 11, $E$ is labeled as the adsorption energy $(\mathrm{kJ} / \mathrm{mol})$, and constant $\mathrm{B}$ gives the mean free energy of adsorption. The values of $E<40 \mathrm{~kJ} / \mathrm{mol}$ suggest physical adsorption, while $E>40 \mathrm{~kJ} / \mathrm{mol}$ denotes chemical adsorption:

$q_{e}=q_{s} \exp \left(-\beta \varepsilon^{2}\right)$

$\varepsilon=R T \ln \left(1+\frac{1}{C_{e}}\right)$

$E=\frac{1}{\sqrt{2 \beta}}$ 


\section{Characterization of the synthesized materials}

The formation of the CNT samples was investigated by X-ray diffraction (XRD) patterns (Phillips PW 1840 X-ray diffractometer with $\mathrm{CuK} \alpha \mathrm{X}$-ray radiation source). The morphology of the synthesized materials was determined by scanning electron microscopy (SEM) instrument utilization of Mira 3-XMU model with accelerating potential $7.0 \mathrm{kV}$. The surface bonding and surface chemical were examined by Fourier transform infrared spectra (FTIR) in the frequency range of $4000-400 \mathrm{~cm}^{-1}$ by $\mathrm{KBr}$ pellets. The surface area and porous characterization were analyzed with $\mathrm{N}_{2}$ adsorption/desorption at $77 \mathrm{~K}$ overnight by Micromeritics ASAP 2010 system using Brunauer-Emmett-Teller (BET) isotherm. To evaluate the stability of the synthesized adsorbents, Thermo gravimetric analysis (TGA) was implemented between 20 and $700{ }^{\circ} \mathrm{C}$ by SDT Q600, UK, with a heating rate of $10{ }^{\circ} \mathrm{C} / \mathrm{min}$ under $\mathrm{N}_{2}$ atmosphere. The functionalization is proven by comparing the weight loss of the pristine $\mathrm{CNT}$ and $\mathrm{COOH}-\mathrm{CNT}$, respectively.

\section{Computational details}

All the spin-restricted DFT calculations were performed using the $\mathrm{DMol}^{3}$ program $[23,24]$. The generalized gradient approximation with the Perdew-Burke-Ernzernhof (PBE) [25] functional was used to treat the exchange-correlation interactions. The Grimme scheme modified the van der Waals interactions effect [26, 27]. A double numerical plus polarization (DNP) basis set was adopted for all atoms. A Fermi smearing parameter of $0.005 \mathrm{Ha}$ was used in the calculations. The convergence tolerance for energy change, maximum force, and maximum displacement were $1 \times 10^{-5} \mathrm{Ha}, 0.001 \mathrm{Ha}^{-1}$, and $0.005 \AA$, respectively. To simulated pure CNT, a large truncated $(6,6)$ single-walled tube containing 204 carbon atoms was constructed. Both ends of the truncated CNT segments were capped with hydrogen atoms to saturate dangling bonds. Then, $\mathrm{COOH}-\mathrm{CNT}$ was obtained by the functionalization of pure $\mathrm{CNT}$ with $\mathrm{COOH}$ groups. The adsorption energy $\left(E_{\mathrm{ads}}\right)$ of each adsorbate was obtained by

$E_{\mathrm{ads}}=E_{\mathrm{IC} / \mathrm{CNT}}-E_{\mathrm{IC}}-E_{\mathrm{CNT}}$

where $E_{\mathrm{IC} / \mathrm{CNT}}, E_{\mathrm{IC}}$, and $E_{\mathrm{CNT}}$ are the total energies of the IC over pure or $\mathrm{COOH}$ functionalized CNT, the IC, and CNT, respectively.

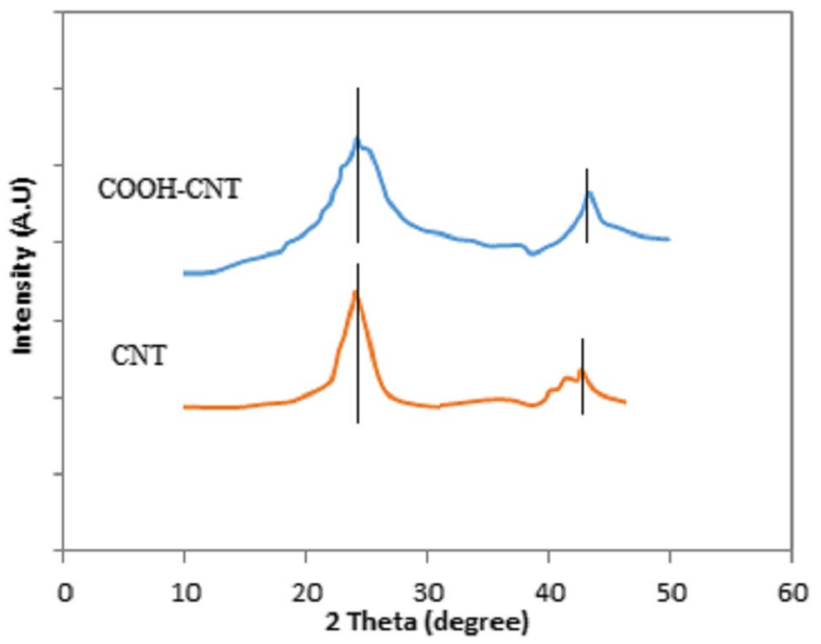

Fig. 2 XRD pattern of the $\mathrm{COOH}-\mathrm{CNT}$ and $\mathrm{CNT}$

\section{Results and discussion}

\section{Characterization of adsorbents}

XRD patterns of the synthesized CNT affirm their graphitic crystal structure, which is due to their inherent property. In Fig. 2, the peaks at $2 \theta=24.9,42.1^{\circ}$, indicating the CNT materials prepared by the CVD method [22-30]. The only difference between the CNT and $\mathrm{COOH}-\mathrm{CNT}$ pattern is the broadening of the peaks. The reason for the peak broadening is the functionalization of the CNT. The functional group interrupts the surface of the CNT wall, and therefore, the crystallinity of the CNTs declines.

The FESEM feature of the CNTs tubes is shown in Fig. 3a, b. As Fig. 3a, b demonstrates, the diameter range of the synthesized CNTs is varied from 12 to $62 \mathrm{~nm}$. Compared to the pristine CNT, the $\mathrm{COOH}-\mathrm{CNT}$ becomes shorter in the FESEM image due to the acid fragment.

The FTIR spectra were recorded to investigate the chemical structure of the pristine CNT and $\mathrm{COOH}-\mathrm{CNT}$. The FTIR records of the pristine CNT and $\mathrm{COOH}-\mathrm{CNT}$ are compared in Fig. 4. The characteristic peaks of the synthesized $\mathrm{COOH}-\mathrm{CNT}$ are presented at 1074, 1718, 1655 , and $3433 \mathrm{~cm}^{-1}$, which can be assigned to $\mathrm{C}-\mathrm{O}$, $\mathrm{C}=\mathrm{C}, \mathrm{C}=\mathrm{O},-\mathrm{OH}$, respectively. It is evident from the comparison of the CNT and COOH-CNT FTIR spectra that the peaks at 1074 and $1718 \mathrm{~cm}^{-1}$ belong to the stretching vibration of $\mathrm{C}=\mathrm{O}$ and $\mathrm{C}-\mathrm{O}$ in the carboxylic group, respectively [28]. The peak around $1635 \mathrm{~cm}^{-1}$ refers to $\mathrm{C}=\mathrm{C}$ graphene sheet bonds of the synthesized CNT. The peaks at 2920 and $2850 \mathrm{~cm}^{-1}$ verify the $\mathrm{C}-\mathrm{H}$ stretch mode of $\mathrm{H}-\mathrm{C}=\mathrm{O}$ in the carboxyl group on the CNT surface. The FTIR peaks for CNT illustrate stretching vibrations of $\mathrm{O}-\mathrm{H}, \mathrm{C}-\mathrm{H}$, and $\mathrm{C}-\mathrm{O}$ at 3430 and 3433 [29]. 


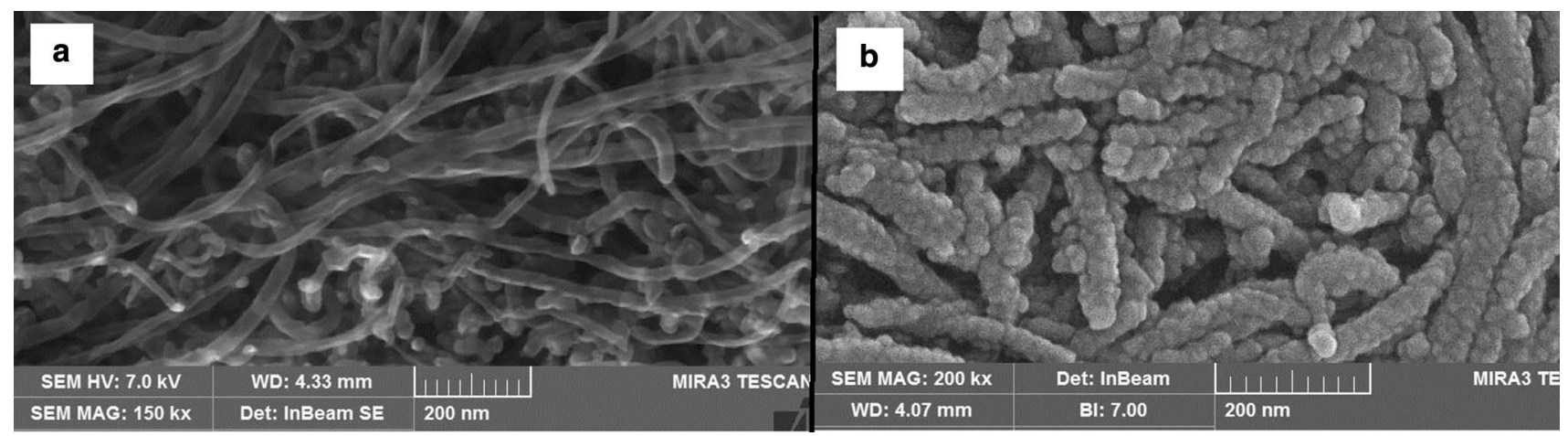

Fig. 3 FESEM image of a CNT, b COOH-CNT

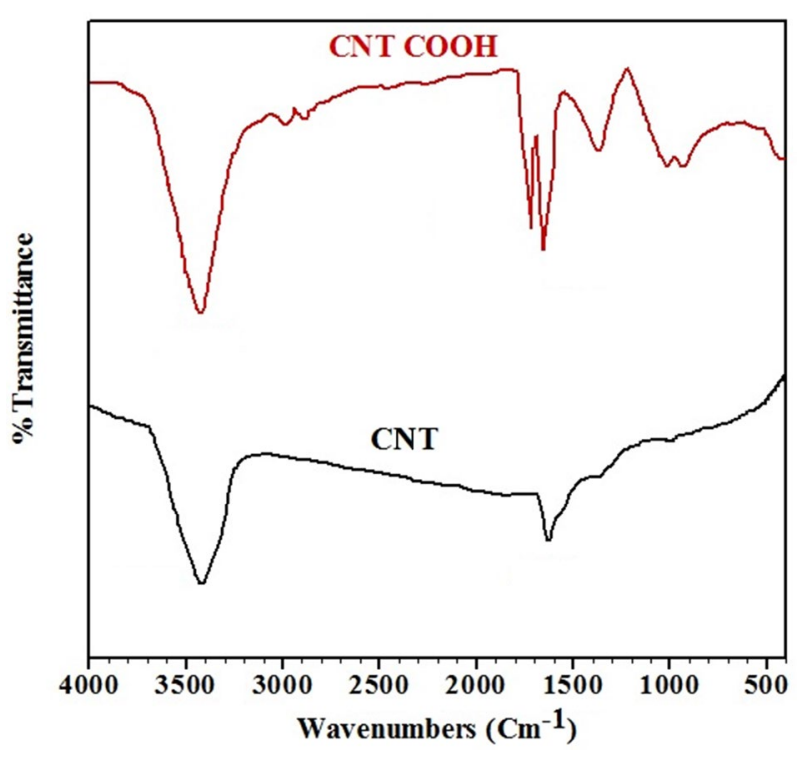

Fig. 4 FTIR spectra of the synthesized adsorbents before adsorption

Table $1 \mathrm{~N}_{2}$ adsorption isotherm data

\begin{tabular}{llll}
\hline Sample & $\begin{array}{l}\text { Surface area } \\
\left(\mathrm{m}^{2} / \mathrm{g}\right)\end{array}$ & $\begin{array}{l}\text { Average pore diam- } \\
\text { eter }(\mathrm{nm})\end{array}$ & $\begin{array}{l}\text { Pore } \\
\text { volume } \\
\left(\mathrm{cm}^{3} / \mathrm{g}\right)\end{array}$ \\
\hline $\mathrm{CNT}$ & 74.2 & 12.79 & 0.34 \\
$\mathrm{COOH}-\mathrm{CNT}$ & 145.90 & 11.34 & 0.45 \\
\hline
\end{tabular}

The surface study parameters such as surface area, pore size, and pore volume of the synthesized adsorbent are listed in Table 1. The characteristic properties such as surface area, pore size, and pore volume are so sensitive for the synthesis protocol. The enhancement of the surface area and pore volume and depletion of the average pore diameter are concluded from data in Table 1. The functionalization seems to be outstanding at controlling the properties that its reason may be responsible for the acidification changes of the CNT walls until the acid treatment.

The pore size distribution is presented in Fig. 5a. The pore size distribution of $\mathrm{COOH}-\mathrm{CNT}$ corresponds to the dominant peaks lower than $50 \mathrm{~nm}$. The $\mathrm{N}_{2}$ adsorption/desorption isotherm at Fig. $5 b$ indicates the mesoporous structure for synthesized adsorbent due to the hysteresis loops of type IV. Examination of the thermal stability, decomposition pattern, and verification of the functionalization carries out by Thermal gravity analysis (TGA). As Fig. 6 indicates, the distinction of the weight loss at $500{ }^{\circ} \mathrm{C}$ for $\mathrm{CNT}$ and $\mathrm{COOH}-\mathrm{CNT}$ is about $8 \%$, which proves the successful functionalization of the carboxylic groups on the CNT surface. The weight loss of $1 \%$ and $5 \%$ below the $145^{\circ} \mathrm{C}$ regards to the evaporation of the absorbed moisture on CNTs surfaces. A considerable weight loss is observed between 145 and $350{ }^{\circ} \mathrm{C}$ that belongs to the decomposition of the carboxyl group and impurities. The third step of the weight loss in the range of $350-500{ }^{\circ} \mathrm{C}$ is related to the dismissal of the oxygen group of the carboxyl that may cause the structural collapse [30]. Removing the amorphous carbons is performed at the temperature above $500{ }^{\circ} \mathrm{C}$.

\section{The effect of adsorbent mass}

The effect of the loaded adsorbent is studied to obtain the optimized adsorbent mass and effectiveness of the adsorbent with the minimum amount. In this part of the experiment, the parallel series of adsorption tests are carried out with $\mathrm{CNT}$ and $\mathrm{COOH}-\mathrm{CNT}$ as adsorbents. Different amounts of adsorbent $(0.1-1 \mathrm{~g})$ are introduced to the IC dye at $100 \mathrm{ppm}$ concentration and $25^{\circ} \mathrm{C}$. Figure 7 shows the effect of adsorbent mass loaded on the dye removal efficiency. The increase of the adsorbent dosage causes the high removal efficiency of the IC dye. The maximum removal efficiency of the IC dye achieves with the use of $0.5 \mathrm{~g}$ of the adsorbent. Comparing the pure $\mathrm{CNT}$ and $\mathrm{COOH}-\mathrm{CNT}$ as an adsorbent, the removal efficiency of the $\mathrm{COOH}-\mathrm{CNT}$ is higher than 

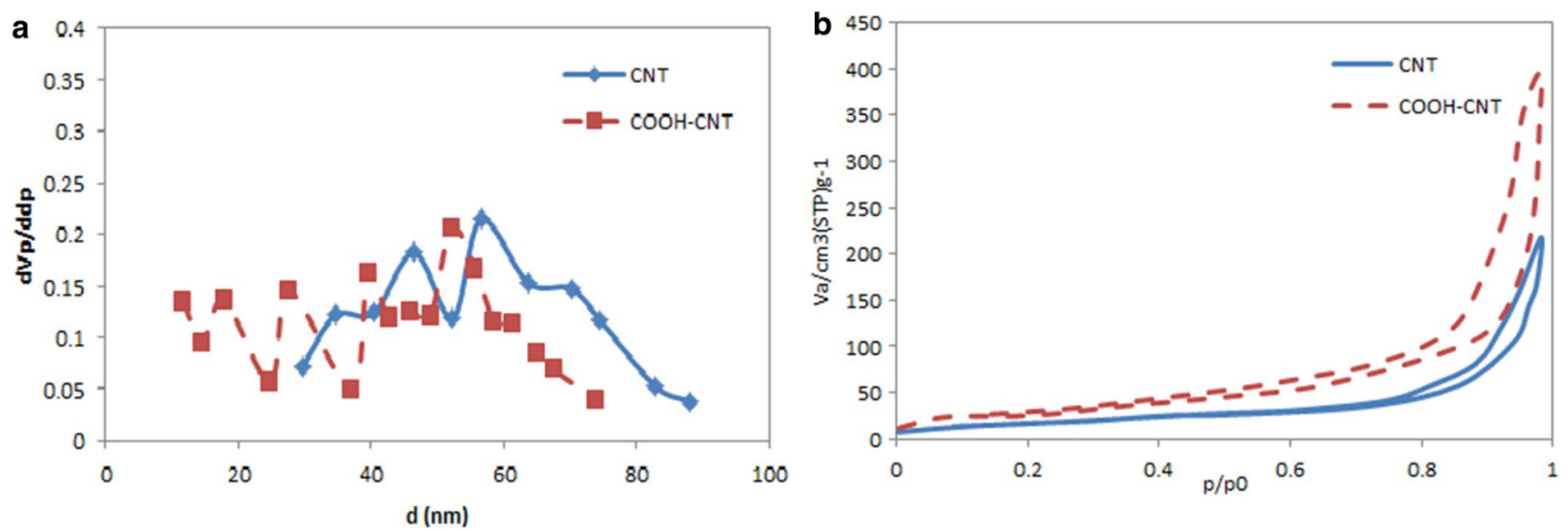

Fig. 5 a Pore size distribution data, $\mathbf{b} \mathrm{N}_{2}$ adsorption/desorption isotherm data

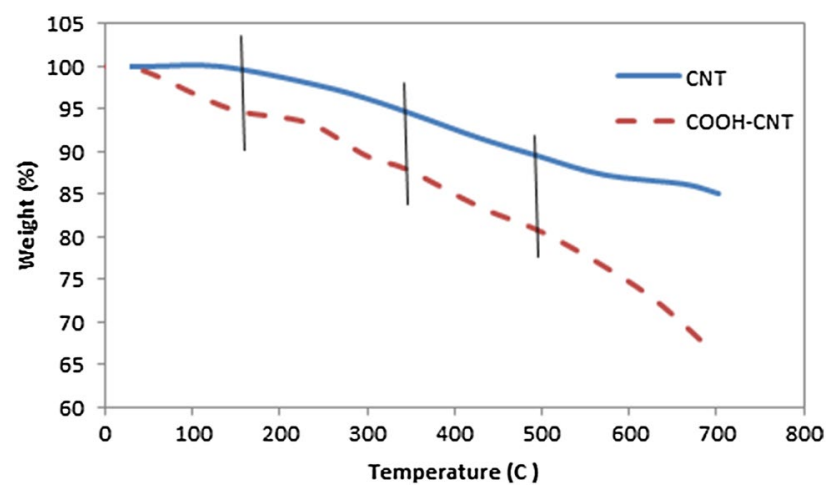

Fig. 6 Thermal gravity analysis of the synthesized adsorbent

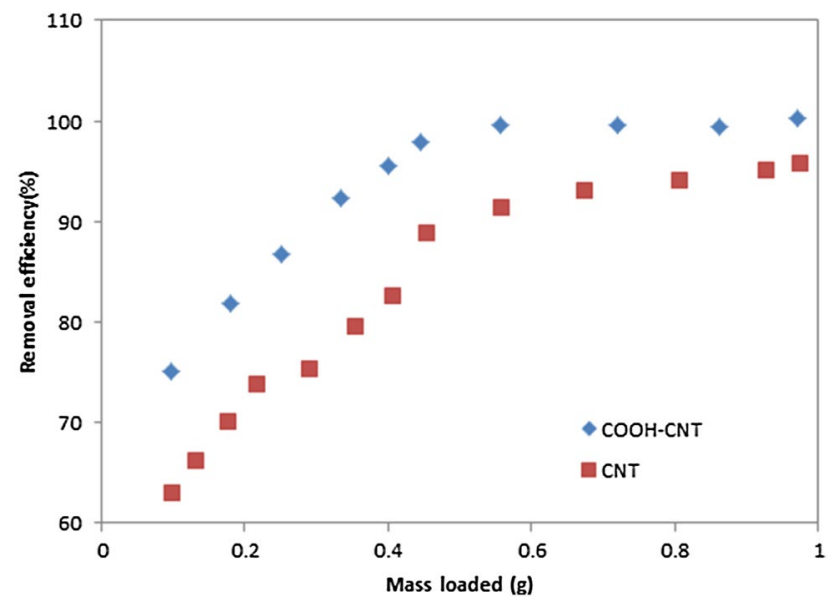

Fig. 7 Effect of the adsorbents mass loaded on the removal efficiency

pure CNT. The CNT and $\mathrm{COOH}-\mathrm{CNT}$ equilibrium capacity were calculated as 88.5 and $136 \mathrm{mg} / \mathrm{g}$ within $15 \mathrm{~min}$ at room temperature for $100 \mathrm{ppm}$ initial concentration of IC dye, respectively.
Laszlo et al. [32] have suggested three mechanisms for the adsorption of aromatic cycles onto the adsorbents. They are (1) electron donor-acceptor interaction between aromatic cycles of the adsorbate and oxygenate groups on the surface of the adsorbent, (2) electrostatic attraction and repulsion between ions of adsorbate and adsorbent, and (3) interaction between $\pi$ electrons of the aromatic structure of the adsorbate and $\pi$ electrons of the graphitic nature of the CNT [33, 34]. The observation of the $\mathrm{COOH}-\mathrm{CNT}$ adsorption mechanism indicates that in addition to IC dye removal by the mentioned mechanisms above, and it also eliminates the IC dye from the liquid phase by hydrogen bonding mechanism, which makes the IC dye removal more quickly. The $-\mathrm{COOH}$ bonding and $-\mathrm{N}-\mathrm{H},-\mathrm{O}-\mathrm{H}$ bonding on the IC dye surface, which has been proven by FTIR spectra, provokes the hydrogen bonding. The FTIR spectra after the adsorption process are recorded in Fig. 8. The broadband about $3400 \mathrm{~cm}^{-1}$ is assigned to the vibration formed by hydrogen-bonded $-\mathrm{O}-\mathrm{H}$ groups in the adsorbent and adsorbate molecules. There is broadband that is presented by the peak at $3390,3433 \mathrm{~cm}^{-1}$ shows the hydrogen bonding in comparison to the FTIR analysis before the adsorption process [35,36]. Due to the aromatic and honey ball structure of pristine CNT, the main interaction of the pristine CNT and IC dye can be considered as the $\pi-\pi$ interaction.

\section{The effect of $\mathrm{pH}$}

The $\mathrm{pH}$ evaluation of the IC dye adsorption on the CNT and $\mathrm{COOH}-\mathrm{CNT}$ is performed in this research. The CNT adsorption capacity is affected by factors such as pore structure, functional groups hydrogen, electrostatic bonding, and $\mathrm{pH}$ [32]. A series of parallel experiments are done to evaluate the effect of the $\mathrm{pH}$ on the IC dye removal utilization of $0.5 \mathrm{~g}$ adsorbent, $100 \mathrm{ppm}$ initial concentration of IC dye at $25^{\circ} \mathrm{C}$. The data of the pH effect on the IC dye 


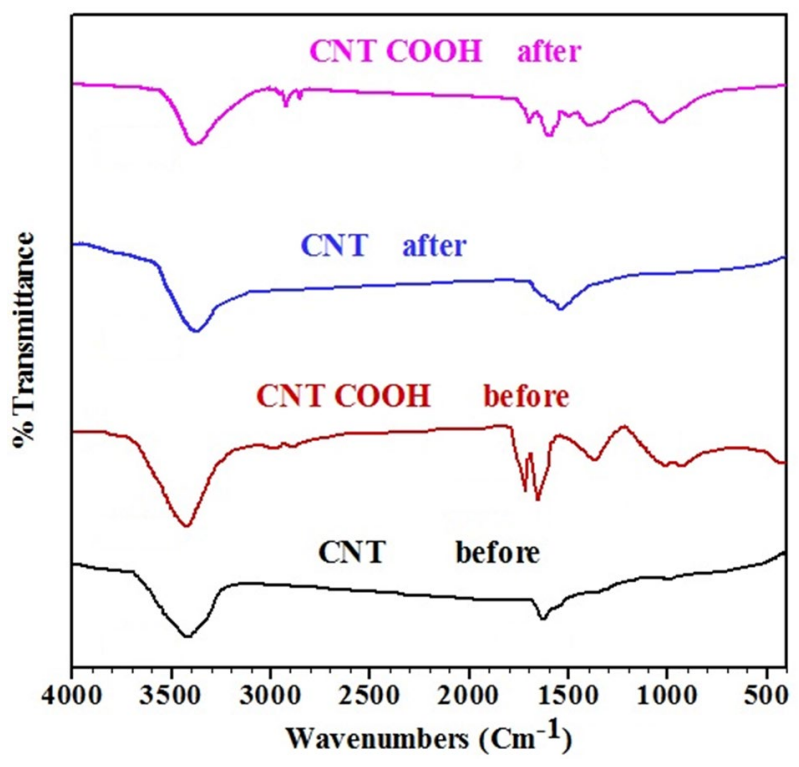

Fig. 8 FTIR spectra of the adsorbents after adsorption process

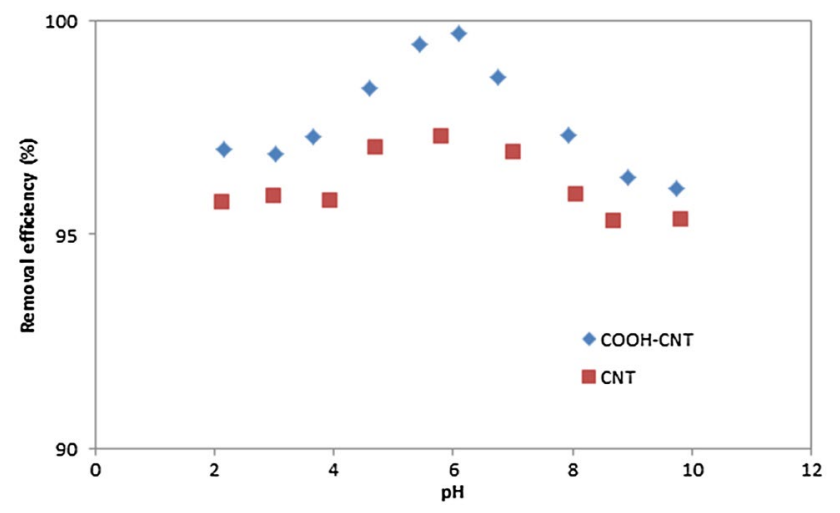

Fig. 9 Effect of the $\mathrm{pH}$ on the removal efficiency of the IC dye

removal onto the adsorbents is plotted in Fig. 9. According to Fig. 9, the optimum value of the $\mathrm{pH}$ is about 6 . This result is explained by considering the adsorbent $\mathrm{pH}$ at the point of zero charges $\left(\mathrm{pH}_{\mathrm{pzc}}\right)$ [28-31]. The $\mathrm{pH}_{\mathrm{pzc}}$ of this experiment is reported at 5.5 [37]. The negative charge of the adsorbent surface in the solution with $\mathrm{pH}$ higher than $\mathrm{pH}_{\mathrm{pzc}}$, which is so efficacious in the adsorption of the cationic dyes. Due to the electrostatic repulsion between the positive charge of the IC dye and negative charge of the carboxyl on the cylindrical surface of the $\mathrm{COOH}-\mathrm{CNT}$, the adsorption capacity of $\mathrm{COOH}-\mathrm{CNT}$ has bigger than pristine CNT.

\section{Adsorption kinetics}

The experiments were performed at different adsorption times, $25{ }^{\circ} \mathrm{C}$ and $100 \mathrm{ppm}$ initial concentration of IC

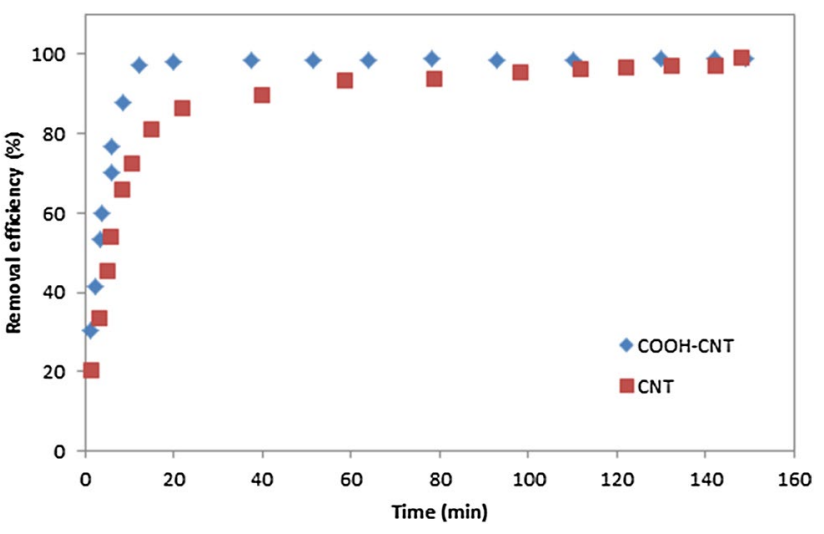

Fig. 10 Effect of time on the removal efficiency of IC dye

dye. Figure 10 represents the effect of contact time on the removal efficiency of IC dye. The removal efficiency of IC dye increases by enhancement of the contact time, but after $15 \mathrm{~min}$, the solution receives to the equilibrium point, so after that point, the removal efficiency becomes constant. As shown in Fig. 10, COOH-CNT receives to the equilibrium time quicker than pristine $\mathrm{CNT}$, as a result of the hydrogen bonding as an adsorption mechanism and more adsorption sites of the $\mathrm{COOH}-\mathrm{CNT}$ because of functionalizing the CNT. The removal efficiency of the IC dye onto $\mathrm{COOH}-\mathrm{CNT}$ is about $98.7 \%$ at $15 \mathrm{~min}$, and for CNT, this result is about $84 \%$ at $15 \mathrm{~min}$. It is concluded that the adsorption mechanism of the IC dye on the CNT is not the same as $\mathrm{COOH}-\mathrm{CNT}$, which is discussed in the previous section.

In this research, three models of the kinetic study are considered. To determine the rate-controlling step of the adsorption process, the linearized forms of these models (Eqs. 3, 4, and 5) are plotted in Figs. s1 and s2. The values of the parameters of the pseudo-first-order model $\left(k_{1}\right.$ and $q_{e}$ ) are calculated for IC dye adsorption onto the CNT and $\mathrm{COOH}-\mathrm{CNT}$. Figures $\mathrm{s} 1 \mathrm{~b}$ and $\mathrm{s} 2 \mathrm{~b}$ show the plot of the pseudo-second-order model where $t / q$ vs. time. The parameters of the pseudo-second-order model $\left(k_{2}\right.$ and $\left.q_{e}\right)$ are listed in Table 2. The intraparticle model is shown in Figs. s1c and $\mathrm{s} 2 \mathrm{c}$. The parameters of this model are obtained from the linearized form where $k_{i}$ is plotted against $t^{1 / 2}$. The observations based on the regression coefficient $\left(R^{2}>0.9\right)$ suggest that pseudo-second-order is a more suitable model than the pseudo-first-order model for adsorption of IC dye onto the $\mathrm{CNT}$ and $\mathrm{COOH}-\mathrm{CNT}$. The summarized data of Table 2 indicate that the calculated equilibrium capacity of the adsorbent is equally as the experimental one in the pseudosecond model for both adsorbents. According to the results, the pseudo-second-order model is fitted well for the kinetic data of the IC dye adsorption onto CNT and $\mathrm{COOH}-\mathrm{CNT}$.

There are steps in the adsorption process: (1) transport from bulk (film) to the external surface of the adsorbent; 
Table 2 Kinetic study data of $\mathrm{CNT}$ and $\mathrm{COOH}-\mathrm{CNT}$

\begin{tabular}{llllll}
\hline Adsorbent & Model & $q_{\text {e-calculated }}(\mathrm{mg} / \mathrm{g})$ & $K_{1}$ & $\begin{array}{l}q_{\text {e-experimental }} \\
(\mathrm{mg} / \mathrm{g})\end{array}$ & $R^{2}$ \\
\hline CNT & Pseudo-first order & 27.11 & $0.3 \times 10^{-1}$ & 89.45 & 0.83 \\
& Pseudo-second order & 88.49 & $1.2 \times 10^{-2}$ & 89.45 & 0.99 \\
& Intraparticle & $C_{i}$ & $k_{\text {id }}$ & - & \\
& First step & 6.85 & 119.72 & - & 0.99 \\
& Second step & 54.93 & 1.73 & - & 0.95 \\
COOH-CNT & Pseudo-first order & 70.81 & $0.38 \times 10^{-1}$ & 136.3 & 0.82 \\
& Pseudo-second order & 135.13 & $9.3 \times 10^{-2}$ & 136.3 & 1 \\
& Intraparticle & $C_{i}$ & $k_{\text {id }}$ & - & 0.99 \\
& First step & 123.5 & 127.7 & - & 0.98 \\
& Second step & 3.78 & 9.38 & - & \\
\hline
\end{tabular}

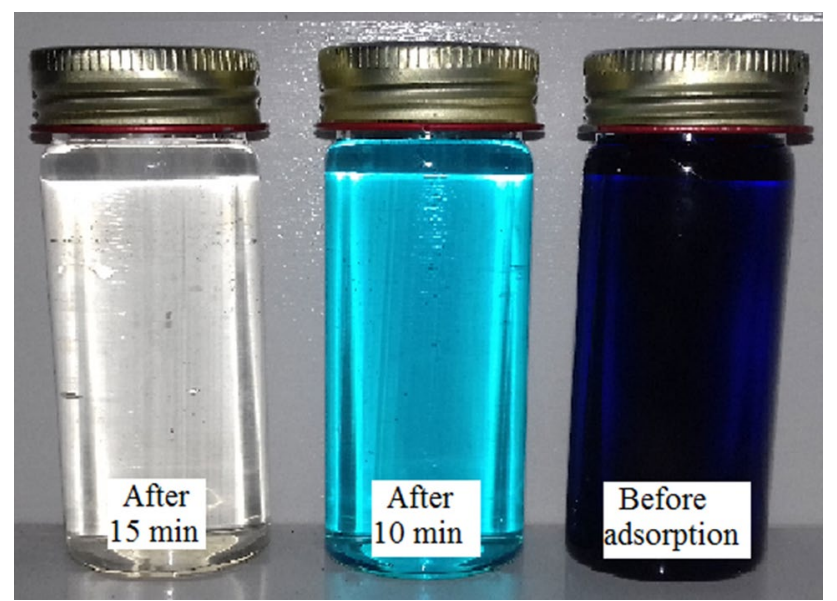

Fig. 11 IC dye solution before and after adsorption in different adsorption times (adsorbent: $\mathrm{COOH}-\mathrm{CNT}$ )

(2) transport from the external surface of the adsorbents to the pores (intraparticle) of the adsorbent; and (3) adsorption of the adsorbate onto the adsorbent surface [38-40]. These facts can be discussed from the intraparticle kinetic model. In Figs. s1c and s2c, two stages of the adsorption process are witnessed, which the first stage with a sharp slope, and the second one is so mild. Besides the data of Table 2, verify this change. The first step is to emphasize the boundary layer effect on the IC dye adsorption onto the adsorbent [41] that is introduced as a fast step in the adsorption process. The second portion is due to the intraparticle diffusion of the IC dye molecules within the $\mathrm{CNT}$ and $\mathrm{COOH}-\mathrm{CNT}$ pores. The second region, because of the slowest portion, is defined as a rate-controlling step. It can be concluded that intraparticle diffusion mass transfer controls the adsorption of the IC dye onto the CNT and $\mathrm{COOH}-\mathrm{CNT}$ as adsorbents. Figure 11 presents samples containing IC dye solution before and after adsorption onto $\mathrm{COOH}-\mathrm{CNT}$ that has been conducted for $10 \mathrm{~min}$, and $15 \mathrm{~min}$.

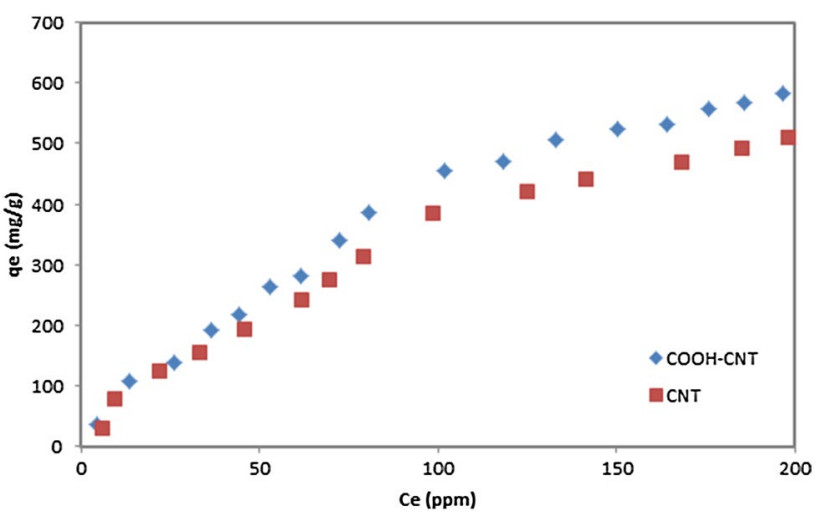

Fig. 12 Effect of initial concentration of IC dye on the adsorbents capacity

\section{Isotherm study}

A parallel series of experiments are performed to determine the effect of IC dye initial concentration on adsorbent capacity using different values of IC dye concentration. The results are shown in Fig. 12. The enhancement of the IC dye initial concentration increases the capacity of the adsorbent. It is because the increase in the driving force increases the mass transfer flux. Besides, the removal efficiency of the IC dye adsorption rises by initial IC dye concentration increase. The high adsorption capacity of the $\mathrm{COOH}-\mathrm{CNT}$ is due to the functional groups compared with that of pristine CNT. In Figs. s3 and s4, the isotherm models are plotted for CNT and $\mathrm{COOH}-\mathrm{CNT}$. The equilibrium data are summarized in Table 3. According to Table 3, the Langmuir isotherm model $\left(R^{2}=1\right)$ is a suitable model for adsorption isotherm data. The homogeneous active site is confirmed in the IC dye adsorption process that is alignment with the Langmuir model assumption. The proper suitability of the equilibrium data with the Langmuir model implies that the monolayer coverage of IC dye adsorption onto the CNT and COOH-CNT. The favorability of the IC dye 
Table 3 Isotherm study of the CNT and $\mathrm{COOH}-\mathrm{CNT}$ for IC dye adsorption

\begin{tabular}{llllll}
\hline Adsorbent & Isotherm model & & & & \\
\hline CNT & Langmuir & $Q_{0}$ & $B$ & $R_{\mathrm{L}}$ & $R^{2}$ \\
& & 434.78 & $2 \times 10^{-2}$ & 0.41 & 1 \\
& Freundlich & $n$ & $k_{F}$ & & \\
& & 1.45 & 12.96 & & 0.84 \\
& Tempkin & $B$ & $A_{T}$ & & \\
& & 381.97 & $6.5 \times 10^{-1}$ & & 0.88 \\
& D-R & $q_{e}$ & $\beta$ & & \\
& & 356.03 & $3.76 \times 10^{-4}$ & & 0.78 \\
COOH-CNT & Langmuir & $Q_{0}$ & $B$ & $R_{\mathrm{L}}$ & $R^{2}$ \\
& & 263.1 & $4.3 \times 10^{-1}$ & 0.53 & 1 \\
& Freundlich & $n$ & $k_{F}$ & & \\
& & 1.94 & 21.77 & & 0.82 \\
& Tempkin & $B$ & $A_{T}$ & & \\
& & 421.76 & $7.8 \times 10^{-1}$ & & 0.85 \\
& D-R & $q_{e}$ & $\beta$ & & \\
& & 458.03 & $5.21 \times 10^{-4}$ & & 0.79 \\
\hline
\end{tabular}

adsorption is assessed with the $R_{\mathrm{L}}$ coefficient. The value of $R_{\mathrm{L}}$ is achieved by $1 /\left(1+b \times C_{0}\right)$. For IC, dye adsorption onto the adsorbents is calculated in Table 3 . According to the literature, $0<R_{\mathrm{L}}<1$ indicates the favorable adsorption process [42-44]. The value of the IC dye adsorption onto the CNT and $\mathrm{COOH}-\mathrm{CNT}$ becomes 0.41 and 0.53 , respectively. As the Tempkin model is focused on the interactions between the adsorbent and adsorbate, this model can be used to elucidate IC dye adsorption on the carbon-based adsorbent.

\section{Desorption and adsorbents regeneration experiments}

A set of desorption experiments was carried out by alkaline and acidic solution for a limited time to check the reusability of the selected adsorbent $(\mathrm{COOH}-\mathrm{CNT})$. In this research, $\mathrm{COOH}-\mathrm{CNT}$ was washed by alkaline solution (sodium hydroxide solution) in soxhlet extractor then was rinsed with the deionized water to reach the neutral $\mathrm{pH}$. The removal efficiency of the selected adsorbent is calculated after each regeneration process; the results are plotted in Fig. 13. It is revealed from Fig. 13 that the removal efficiency (\%) is decreased after the eight cycle regeneration process. In the first-to-sixth cycle, the removal efficiency of the IC dye has not changed noticeably, but after the sixth cycle, the removal efficiency is declined to $70 \%$. FESEM image in Fig. 14 is shown after eight cycle regeneration; the adsorption capacity is reduced due to the destruction of the active sites of the adsorbent. In Table 4, the comparison of the adsorption capacities of different adsorbents for dye adsorption is summarized. In comparison with other synthesized adsorbents,

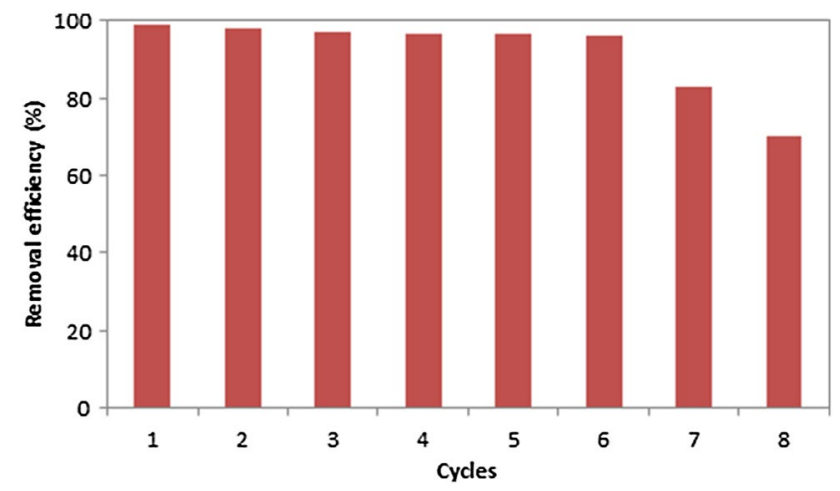

Fig. 13 Comparison of regeneration cycles and removal efficiency

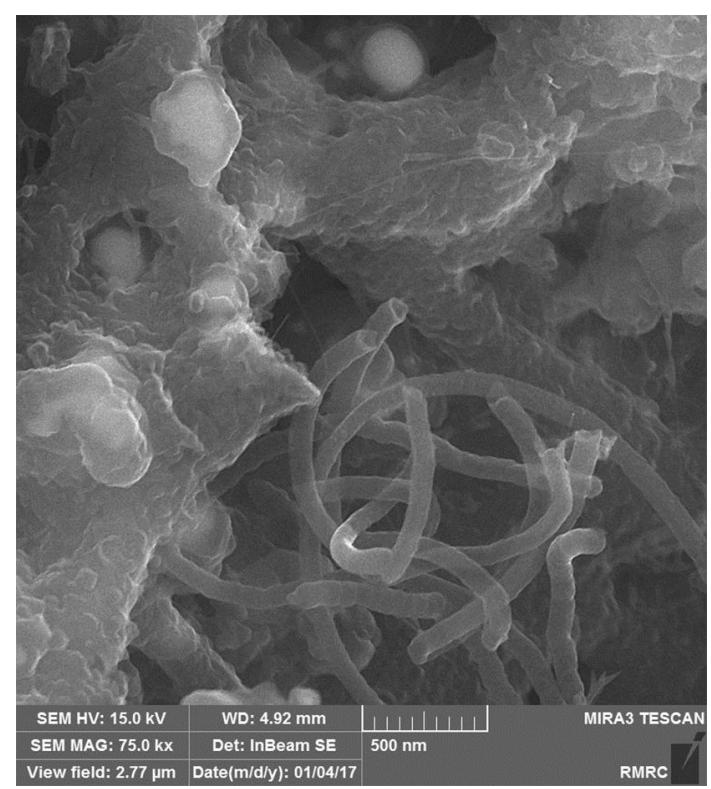

Fig. 14 SEM image of the $\mathrm{COOH}-\mathrm{CNT}$ adsorbent after eight cycle regeneration

Table 4 Comparison between the adsorption capacities

\begin{tabular}{lcll}
\hline Adsorbent & $\begin{array}{l}\text { Capacity } \\
(\mathrm{mg} / \mathrm{g})\end{array}$ & $\begin{array}{l}\text { Reusability } \\
(\text { cycle })\end{array}$ & References \\
\hline Activated carbon & 65 & 6 & {$[1]$} \\
Bagasse fly ash & 79 & 4 & {$[22]$} \\
Carbonaceous material & 24 & - & {$[10]$} \\
Mesoporous carbon & 21 & - & {$[11]$} \\
COOH-CNT & 136 & 8 & This work \\
\hline
\end{tabular}

the CNT based adsorbents have an excellent potential to adsorption-desorption process. 


\section{DFT results}

To obtain a detailed understanding of the adsorption mechanism of IC over pure and $\mathrm{COOH}$ functionalized CNTs, highlevel DFT calculations were performed on some appropriate model compounds. Taking the armchair $(6,6) \mathrm{CNT}$ as the representative, the adsorption of IC molecule on both pure and $\mathrm{COOH}-$ functionalized CNTs was compared in detail. Figure s5 of Supporting Information shows the optimized structure of truncated $(6,6)$ pure and $\mathrm{COOH}$-functionalized CNTs. The calculated average $\mathrm{C}-\mathrm{C}$ bond distance in the pure CNT is about $1.43 \AA$, which is in excellent agreement with the previous theoretical reports $[45,46]$. According to our results, the attachment of $-\mathrm{COOH}$ groups on the surface and edges of CNT are energetically favorable. The average adsorption energy of the $\mathrm{COOH}$ group on the pure CNT is about $-130 \mathrm{~kJ} / \mathrm{mol}$, which is good agreement with that obtained in the earlier theoretical studies [47]. Note that this value is the highest (more negative) among all other possible configurations, most likely due to the less steric repulsion between the $\mathrm{COOH}$ groups. Meanwhile, the attachment of $\mathrm{COOH}$ pulls out the $\mathrm{C}$ atom of CNT a little from the tube wall, leading to a local rehybridization at the adsorption site. Consequently, a small radial distortion appears on the tube wall, as shown in Fig. s5. Besides, the electron density analysis of pure and $\mathrm{COOH}$-modified CNTs indicates that the addition of $\mathrm{COOH}$ groups tends to induce some charge redistribution above the CNT surface. There is also a quite small charge transfer $(\approx 0.08$ e, according to the Mulliken charge density analysis) from each $\mathrm{COOH}$ group to the CNT, indicating that the CNT acts as an electron acceptor in $\mathrm{COOH}-\mathrm{CNT}$. Besides, the regions with the smallest electron density in $\mathrm{COOH}-\mathrm{CNT}$ are associated with the hydrogen atom of $\mathrm{COOH}$ groups, which implies the potential of these sites to interact with electron-rich moieties.

Figure 15 shows the most stable configuration of the IC molecule over pure and $\mathrm{COOH}$-functionalized CNTs. As seen, the IC molecule adopts almost a parallel configuration over the pure CNT, with a binding distance of $3.35 \AA$. The corresponding adsorption energy is calculated to be $-69.7 \mathrm{~kJ} /$ mol, which indicates that the IC molecule is stably adsorbed over the pure CNT. As noted above, the main driving force for the adsorption of IC over the pure CNT is the attractive $\pi-\pi$ stacking interactions between the aromatic rings of IC and the delocalized electronic $\pi$ cloud of the CNT. Due to this weak interaction, a negligible charge $(0.15 \mathrm{e})$ transfers from the IC to the CNT. Due to our DFT results, the IC is firmly attached to the $\mathrm{COOH}$ groups of $\mathrm{COOH}-\mathrm{CNT}$ via the formation of hydrogen-bonding interactions (Fig. 15b). In addition to these hydrogen-bonding interactions, one can also expect that the functionalization of the $\mathrm{CNT}$ with the $\mathrm{COOH}$ groups enhances the strength of $\pi-\pi$ interaction between the IC and CNT due to the polarization of the tube surface. The adsorption energy
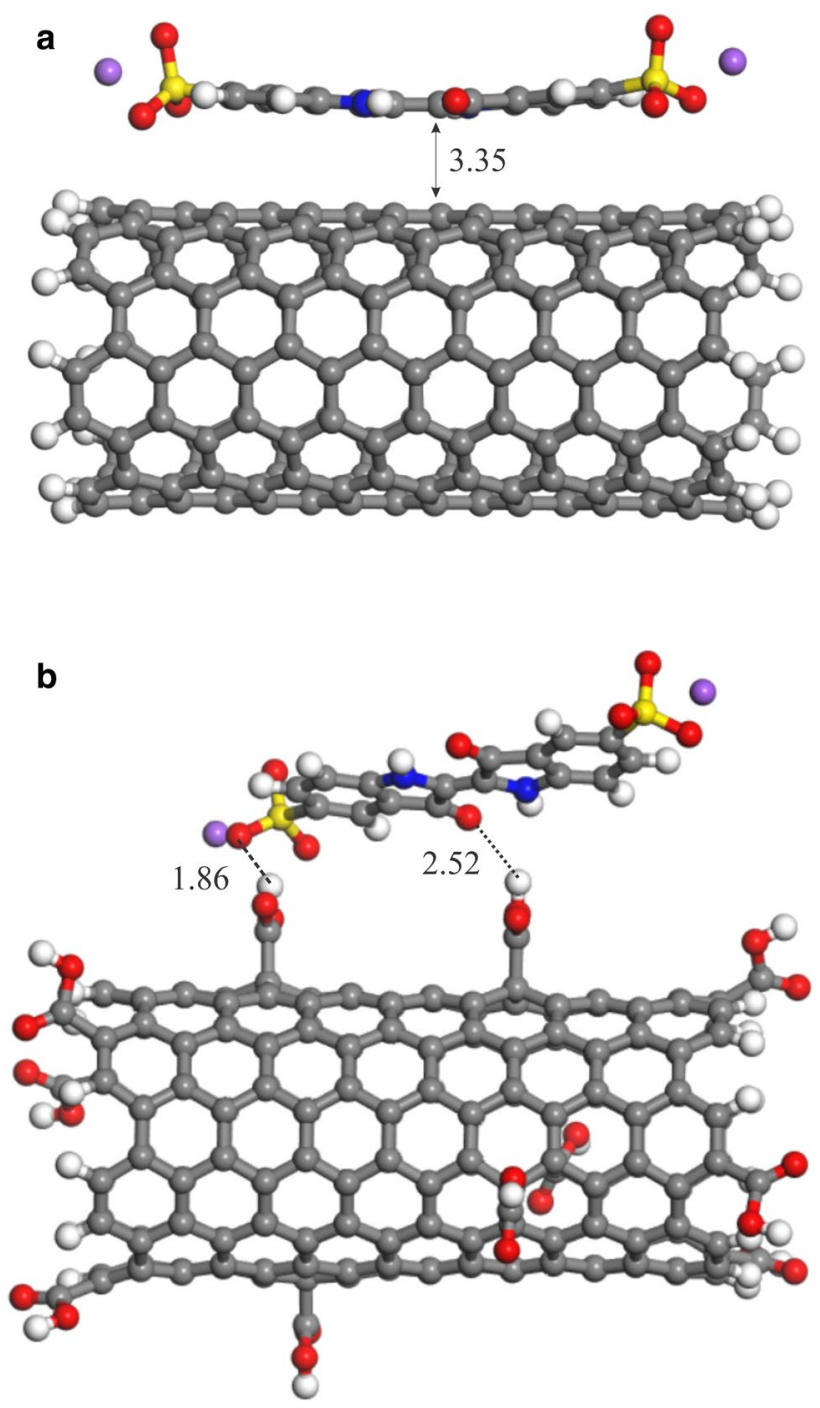

Fig. 15 Optimized structure of IC over, a pure CNT and b $\mathrm{COOH}-$ CNT. The dashed line indicates the hydrogen bond interaction (in $\AA$ )

of IC over the $\mathrm{COOH}-\mathrm{CNT}$ is $-180.5 \mathrm{~kJ} / \mathrm{mol}$, which is much larger than that of over pure CNT. This indicates that the presence of $\mathrm{COOH}$ groups activates the surface of CNT towards the IC molecule. Consequently, the $\mathrm{COOH}-\mathrm{CNT}$ s can be regarded as promising and potential materials to remove IC molecule from wastewater.

\section{Conclusion}

In the present research, the deep adsorptive removal of IC dye from the liquid phase was carried out using the pure $\mathrm{CNT}$ and $\mathrm{COOH}-\mathrm{CNT}$ as adsorbents. A parallel series of adsorption experiments were done to investigate and optimize the process parameters. We found that compared to the pure $\mathrm{CNT}$, the $\mathrm{COOH}-\mathrm{CNT}$ exhibits more considerable 
potential for IC dye removal from wastewater. The adsorption mechanism of the pristine CNT was obtained as the $\pi-\pi$ interaction between the adsorbate and adsorbent. In addition to this mechanism, the adsorption of IC over $\mathrm{COOH}-\mathrm{CNT}$ proceeds via the formation of hydrogen bonding interaction, which causes a fast adsorption process compared to the pristine CNT. The mass of the adsorbent loaded as an adsorption parameter was evaluated, and the optimum amount was $0.5 \mathrm{~g}$. The equilibrium capacity of the CNT and $\mathrm{COOH}-\mathrm{CNT}$ was 88.5 and $136 \mathrm{mg} / \mathrm{g}$ within $15 \mathrm{~min}$ at room temperature for $100 \mathrm{ppm}$ initial concentration of IC dye. The Langmuir model was so suitable for the equilibrium data, which was indicated the monolayer adsorption process. The $\mathrm{R}_{\mathrm{L}}$ coefficient of the Langmuir was 0.53 for $\mathrm{COOH}-\mathrm{CNT}$, focused on the favorable adsorption process. The kinetic data were fitted the pseudo-second-order model well, which indicated the chemisorption process for IC dye adsorption removal. The rate-controlling step of the IC dye adsorption was substantiated in the pore diffusion and intraparticle step. Moreover, CNT-based adsorbents presented good reusability behavior. The DFT calculations revealed that the functionalization of CNT with $\mathrm{COOH}$ groups enhances the adsorption energy of the IC via the formation of hydrogen-bonding interactions. In conclusion, $\mathrm{CNT}$ was a promising alternative for IC dye removal from wastewater.

Open Access This article is distributed under the terms of the Creative Commons Attribution 4.0 International License (http://creativeco mmons.org/licenses/by/4.0/), which permits unrestricted use, distribution, and reproduction in any medium, provided you give appropriate credit to the original author(s) and the source, provide a link to the Creative Commons license, and indicate if changes were made.

\section{References}

1. Vadivelan, V., Kumar, K.V.: Equilibrium, kinetics, mechanism, and process design for the sorption of methylene blue on rice husk. J. Coll. Interf. Sci. 286, 90-100 (2005)

2. Younes, S.B., Sayadi, S.: Detoxification of Indigo carmine using a combined treatment via a novel trimeric thermostable laccase and microbial consortium. J. Mol. Catal. B. Enzym. 87, 62-68 (2013)

3. Forgacs, E., Cserháti, T., Oros, G.: Removal of synthetic dyes from wastewaters: a review. Environ. Int. 7, 953-971 (2004)

4. Ullah, F., Bisyrul, M., Othman, H., Javed, F., Ahmad, Z., Akil, H.M.: Classification, processing and application of hydrogels: a review. Mater. Sci. Eng. Part. C. 57, 414-433 (2015)

5. Liu, C., Wang, G., Sui, W., An, L., Si, C.: Preparation and characterization of chitosan by a novel deacetylation approach using glycerol as green reaction solvent. ACS. Sustain. Chem. Eng. 5, 4690-4698 (2017)

6. Ahmed, E.M.: Hydrogel: preparation, characterization, and applications: a review. J. Adv. Res. 6, 105-121 (2015)

7. Ahsan, M.A., Fernandez-Delgado, O., Deemer, E., Wang, H., ElGendy, A.A., Curry, M.L., Noveron, J.C.: Carbonization of CoBDC MOF results in magnetic $\mathrm{C} @$ Co nanoparticles that catalyze the reduction of methyl orange and 4-nitrophenol in water. J. Mol. Liq. 290, 111059-111068 (2019)

8. Ahsana, M.A., Deemer, E., Fernandez-Delgadoa, O., Wang, H., Curry, M.L., El-Gendye, A.A., Noveron, J.C.: Fe nanoparticles encapsulated in MOF-derived carbon for the reduction of 4-nitrophenol and methyl orange in water. Cat. Comu. 130, 105753-105759 (2019)

9. Ahsan, M.A., Jabbari, V., El-Gendy, A., Curry, M., Noveron, J.: Ultrafast catalytic reduction of environmental pollutants in water via MOF-derived cu and magnetic Ni nanoparticles encapsulated in porous carbon. App. Surf. Sci. 497, 143608143624 (2019)

10. Ahsan, M.A., Jabbari, V., Islam, M.T., Kim, H., HernandezViezcasa, J.A., Lin, Y., Díaz-Moreno, C.A., Lopez, J., GardeaTorresdey, J., Noveron, J.C.: Green synthesis of a highly efficient biosorbent for organic, pharmaceutical, and heavy metal pollutants removal: engineering surface chemistry of polymeric biomass of spent coffee waste. J. Water. Proc. Eng. 25, 309-319 (2018)

11. Ahsan, M.A., Islam, M.T., Imam, M.A., Hyder, A.G., Jabbari, V., Dominguez, N., Noveron, J.C.: Biosorption of bisphenol A and sulfamethoxazole from water using sulfonated coffee waste: isotherm, kinetic and thermodynamic studies. J. Environ. Chem. Eng. 6, 6602-6611 (2018). https://doi.org/10.1016/j.jece.2018.10.004

12. Meshkat, S.S., Tavakoli, O., Rashidi, A.M., Esrafili, M.D.: Adsorptive mercaptan removal of liquid phase using nanoporous graphene: equilibrium, kinetic study and DFT calculations. Ecotox. Environ. Safe. 165, 533-539 (2018)

13. Senthilkumar, S.: Adsorption of methylene blue onto jute fibre carbon, kinetics and equilibrium studies. J. Coll. Interf. Sci. 284, 78-82 (2005)

14. Lin, D.H., Xing, B.: Adsorption of phenolic compounds by carbon nanotubes: role of aromaticity and substitution of hydroxyl groups. Environ. Sci. Technol. 42, 7254-7259 (2008)

15. Wang, H.J., Zhou, A.L., Peng, F., Yu, H., Chen, L.F.: Adsorption characteristic of acidified carbon nanotubes for heavy metal $\mathrm{Pb}$ (II) in aqueous solution. Mater. Sci. Eng. A. 466, 201-206 (2007)

16. Beltrán-Heredia, J., Sánchez-Martín, J., Delgado-Regalado, A.: Removal of carmine indigo dye with Moringa oleifera seed extract. Ind. Eng. Chem. Res. 48, 6512-6520 (2009)

17. Agarwal, S., Tyagi, I., Gupta, V., Bagheri, A., Ghaedi, M., Asfaram, A., Hajati, S., Bazrafshan, A.: Rapid adsorption of ternary dye pollutants onto copper (I)oxide nanoparticle loaded on activated carbon: experimental optimization via response surface methodology. J. Environ. Chem. Eng. 4, 1769-1779 (2016)

18. Kafshgari, L.A., Ghorbani, M., Azizi, A., Agarwal, S., Gupta, V.K.: Modeling and optimization of direct red 16 adsorption from aqueous solutions using nanocomposite of MnFe2O4/MWCNTs: RSM-CCRD model. J. Mol. Liq. 233, 370-377 (2017)

19. Rashidi, A.M., Akbarnejad, M.M., Khodadadi, A.A., Mortazavi, Y., Ahmadpour, A.: Single-wall carbon nanotubes synthesized using organic additives to Co-Mo catalysts supported on nanoporous $\mathrm{MgO}$. Nanotechnology. 18, 315605-315610 (2007)

20. Hoseini-Dastgerdi, Z., Meshkat, S.S.: Experimental and modeling study of asphaltene adsorption by carbon nanotubes from model oil solution. J. Pet. Sci. Eng. 174, 1053-1061 (2019)

21. Ahsan, M.A., Jabbari, V., Imam, M.A., Castro, E., Kim, H., Curry, M.L., Valles-Rosales, D.J., Noveron, J.C.: Nanoscale nickel metal organic framework decorated over graphene oxide and carbon nanotubes for water remediation. Sci. Total. Environ. 698, 134214-134225 (2020)

22. Meshkat, S.S., Tavakoli, O., Rashidi, A.M.: Removal of mercaptan from natural gas condensate using $\mathrm{N}$-doped carbon nanotube adsorbents: kinetic and DFT study. J. Nat. Gas. Sci. Eng. 55, 288-297 (2018) 
23. Delley, B.: An all-electron numerical method for solving the local density functional for polyatomic molecules. J. Chem. Phys. 92, 508-517 (1990)

24. Ahsan, M.A., Jabbari, V., Islam, M.T., Turley, R.S., Dominguez, N., Kim, H., Castro, E., Hernandez-Viezcas, J.A., Curry, M.L., Lopez, J., Gardea-Torresdey, J.L., Noveron, J.C.: Sustainable synthesis and remarkable adsorption capacity of $\mathrm{MOF} / g r a p h e n e$ oxide and MOF/CNT based hybrid nanocomposites for the removal of bisphenol A from water. Sci. Total. Environ. 673, 306-317 (2019)

25. Yang, Y., Xie, Y., Pang, L.: Preparation of reduced graphene oxide/poly(acrylamide) nanocomposite and its adsorption of $\mathrm{Pb}$ (II) and methylene blue. Langmuir. 29, 10727-10736 (2013)

26. Grimme, S.: Accurate description of van der Waals complexes by density functional theory including empirical corrections. J. Comput. Chem. 25, 1463-1473 (2004)

27. Grimme, S.: Semiempirical GGA-type density functional constructed with a long-range dispersion correction. J. Comput. Chem. 27, 1787-1799 (2006)

28. Kuan, H.C., Ma, C.C.M., Chang, W.P., Yuen, S.M., Wu, H.H., Lee, T.M.: Synthesis, thermal, mechanical and rheological properties of multiwall carbon nanotube/waterborne polyurethane nanocomposite. Compos. Sci. Technol. 65, 1703-1712 (2005)

29. Abuilaiwi, A., Laoui, T., Al-Harthi, M., Mautaz, A.A.: Modification and functionalization of multiwalled carbon nanotube (MWCNT) via fischer esterification. Arab. J. Sci. Eng. 35, 37-46 (2010)

30. Martın, O., Gutierrez, H.R., Maroto-Valiente, A., Terrones, M., Blanco, T., Baselga, J.: An efficient method for the carboxylation of few-wall carbon nanotubes with little damage to their sidewalls. Mater. Chem. Phys. 140, 499-507 (2010)

31. Datsyuk, V., Kalyva, M., Papagelis, K., Parthenios, J., Tasis, D., Siokou, A.: Chemical oxidation of multiwalled carbon nanotubes. Carbon. 46, 833-840 (2008)

32. Laszlo, K., Podkoscielny, P., Dabrowski, A.: Heterogeneity of polymer-based active carbons in the adsorption of aqueous solutions of phenol and 2,3,4-trichlorophenol. Langmuir. 19, 5287-5294 (2003)

33. Senthilkumaar, S., Kalaamani, P., Subburaam, C.V.: Liquidphase adsorption of crystal violet onto activated carbons derived from male flowers of coconut tree. J. Hazard. Mater. B. 136, 800-808 (2006)

34. Terzyk, A.P.: Further insights into the role of carbon surface functionalities in the mechanism of phenol adsorption. J. Colloid. Interface. Sci. 268, 301-329 (2003)

35. Terzyk, A.P., Rychlicki, G., Biniak, S., Lukaszewicz, J.P.: New correlations between the composition of the surface layer of carbon and its physicochemical properties exposed while paracetamol is adsorbed at different temperatures and $\mathrm{pH}$. J. Colloid. Interface. Sci. 257, 13-30 (2003)
36. Stavropoulos, G.G., Samaras, P., Sakellaropoulos, G.P.: Effect of activated carbons modification on porosity surface and phenol adsorption. J. Hazard. Mater. 151, 414-421 (2008)

37. Karimi-Jashni, A., Narbaitz, R.M.: Impact of $\mathrm{pH}$ on the adsorption and desorption kinetics of 2-nitrophenol on activated carbon. Water. Res. 31, 3039-3044 (1997)

38. Daifullah, A.A.M., Girgis, B.S.: Removal of some substituted phenols by activated carbon obtained from agricultural. Waste. Water. Res. 32, 1169-1177 (1998)

39. Weber, W.J., Morris, J.C.: Kinetics of adsorption on carbon from solution. J. Sanit. Eng. Div. Am. Soc. Civ. Eng. 89, 31-60 (1963)

40. Kennedy, L.J., Vijaya, J.J., Kayalvizhi, K., Sekaran, G.: Adsorption of phenol from aqueous solutions using mesoporous carbon prepared by two-stage process. Chem. Eng. J. 132, 279-287 (2007)

41. Golder, A.K., Samanta, A.N., Ray, S.: Anionic reactive dye removal from aqueous solution using a new adsorbent-sludge generated in removal of heavy metal by electrocoagulation. Chem. Eng. J. 122, 107-115 (2006)

42. Yamamoto, K., Yoshida, S., Kadokawa, J.: Surface-initiated atom transfer radical polymerization from chitin nanofiber macroinitiator film. Carbohyd. Polym. 112, 119-124 (2014)

43. Guo, J., Yang, W., Wang, C.: Magnetic colloidal supraparticles: design, fabrication and biomedical applications. Adv. Mater. 25, 5196-5214 (2013)

44. Gupta, V.K., Tyagi, I., Agarwal, S., Moradi, O., Sadegh, H., Shahryari-Ghoshekandi, R., Garshasbi, A.: Study on the removal of heavy metal ions from industry waste by carbon nanotubes: effect of the surface modification-a review. Crit. Rev. Environ. Sci. Technol. 15, 1-26 (2015)

45. Gallo, M., Favila, A., Glossman-Mitnik, D.: DFT studies of functionalized carbon nanotubes and fullerenes as nanovectors for drug delivery of antitubercular compounds. Chem. Phys. Lett. 447, 105-109 (2007)

46. Shirvani, B.B., Beheshtian, J., Esrafili, M.D., Hadipour, N.L.: DFT study of NH3 adsorption on the $(5,0),(8,0),(5,5)$ and $(6$, 6) single-walled carbon nanotubes. Calculated binding energies, NMR and NQR parameters. Phys. B. 405, 1455-1460 (2010)

47. Wang, C., Zhou, G., Liu, H., Wu, J., Qiu, Y., Gu, B.L., Duan, W.: Chemical functionalization of carbon nanotubes by carboxyl groups on Stone-Wales defects: a density functional theory study. J. Phys. Chem. B. 110, 10266-10271 (2006)

Publisher's Note Springer Nature remains neutral with regard to jurisdictional claims in published maps and institutional affiliations. 